\title{
Modified Weighted Sum Method for Decisions with Altered Sources of Information
}

\author{
Shahryar Sorooshian ${ }^{1, *}$, Yasaman Parsia ${ }^{2}$ \\ ${ }^{1}$ School of Business Economics and Law, University of Gothenburg, Gothenburg, Sweden \\ ${ }^{2}$ Earth Resources \& Sustainability Centre (ERAS), Universiti Malaysia Pahang, Pahang, Malaysia
}

Copyright $\odot 2019$ by authors, all rights reserved. Authors agree that this article remains permanently open access under the terms of the Creative Commons Attribution License 4.0 International License

\begin{abstract}
Multi Attribute Decision Making (MADM) is an asset to provide solutions for our todays' complex issues and problems. The fact of the matter is that the main source of information in many MADMs is a panel of experts. However, in some cases, there is a possibility of lack of knowledge by the panel to rank or weight one or a few particular criterion/criteria for the decision making. Therefore, the decision maker needs an altered source of information to complete the decision making process. Hence, WSM (Weighted Sum Method) by means of the most popular MADM techniques is selected; and as a prior aim of this article, a modified version of the WSM is proposed as a solution for multiple criteria decision makers by way of a solution for the cases when there is a need for another source of information to rank or weight the particular criterion/criteria. The modified WSM is presented in five stages. The validity, through feasibility, of the modified WSM is tested and verified in a numerical example. Additionally, following this article, future researches could use the same approach for modification of other MADMs to deal with two or more sources of information.
\end{abstract}

Keywords Multi-criteria Decision Making, MADM, WSM, Information

\section{Introduction}

According to Aruldoss, Lakshmi, and Venkatesan [1], many daily decisions are being made from different criteria, thus, one can make a decision by giving weights to these various decision criteria. Identifying the structure of the problem is vital, as well as the explicit evaluation of multi criteria [1]. According to Ansah et al. [2] and Almulhim [3], Multi-Criteria Decision Making (MCDM) is considered as one of the most popular decision making branches of over the last thirty years, it has been used to solve decision problems given the existence of multiple alternatives and criteria. According to Almulhim [3] and Zavadskas et al. [4], MCDM is now one of the most significant and rapidly growing subfields of management science and operations research, as it combines computational and mathematical tools to subjectively assess the performance criteria by decision-makers. It makes use of a general class of operations research models that take into account the decision making problems when there are several decision criteria [2]. Between two categories of MCDM, Multi Attribute Decision Making (MADM) techniques are considered to be one of the support approaches for decision-making, and are regarded to be the base for several decision-making techniques [2]. These techniques are based on a list of chosen criteria, the alternatives available, and the variables that can be considered by a decision-maker in the decision-making process [2,5]. Therefore, alternatives are defined for MADMs and the decision-makers have to merely evaluate and rank the present alternatives [6]. A few examples of MADM are supplier selection, manufacturing decisions, project management, business management decisions and so on (for example, [7-12]). To evaluate an alternative, a criterion is defined for every attribute and the attribute is weighted/examined/ranked based on that criterion [3].

The Weighted Sum Method (WSM) derived from the MADM methods, also known as Factor Rating [13], Simple Scoring Method, or Simple Additive Weighting (SAW) [14], is a broadly popular, widely known and practically used, and readily implemented subjective multi-criteria decision-making method that can be easily executed [13-16]. Among MADMs, WSM is suggested for practitioners who have less knowledge of mathematics [17]. According to Kumar and Suresh [18], this method constitutes of decision practices and methods where every alternative has to be assigned a score depending on a relevant criterion, where every criterion is weighed based on importance. The methodical application involves ascertaining the highest scores for all criteria, finding the 
diverse levels of different criteria, and assigning appropriate scores for every level. Considering the range of attributes, the values and requirements associated with a specific component, the process of shortlisting or screening the criteria requires combining and relating the data to establish a recommendation or ranking. In several studies, the WSM was applied to arrive at a value by totaling the attribute values multiplied by their respective relevant weights $[19,20]$. The alternatives in WSM have an assigned score against every selection criterion and weight applied for each criterion is considered prior to the weighted sum. This is the reason why the MADM method is criticised to constitute of the sum of varying forms of information, to have an absence of any process for finding attribute weights, and to have an inherent issue with the creation of mislaying dependency information between the attributes [19].

Thus, it is established that one of the major constraints of the WSM and other MADMs is their inability to process information from different sources. For instance, these are not applicable in decision-making situations that involve multiple criteria where decision-making groups or experts are not aware of or familiar with certain specific criteria (or at least one criterion) because of incomplete or limited awareness, knowledge, expertise, or other reasons. Hence, the decision-making process consists of two groups of criteria, the decision criteria from a common information source, generally from a group of experts, and the specific criteria with a different information source. To conclude, the prime objective of this article is to improve or modify the WSM, so that it is able to handle and process the described decision cases that arise from a different source of information.

\section{Method}

Sorooshian [13] identified five steps for WSM implementation in classic decision-makings. On the bases of his article, below are the proposed modifications for WSM as a solution for the discussed MADM drawback.

Step 1: First decide priorities for the criteria according to their importance in decision-making. By focusing on the decided priorities, weightings $\left(\mathrm{W}_{\mathrm{x}}\right)$ in percentages can be assigned to every criterion so long as the total weight equals $100 \%$.

Step 2-1: For each alternative, assign a numeric value (V) based on each criterion. With this step, the alternatives set are represented by the decision matrix $\left[\mathrm{V}_{\mathrm{ij}}\right]$, wherein $\mathrm{V}_{\mathrm{ij}}$ denotes the numeric value that expresses how efficiently alternative $A_{x}$ could attain criterion $C_{y}$. Any uniform scale could be used for $\mathrm{V}$ matrix.

Step 2-2: Use of other source(s) of information like available statistics and reports, or other qualitative or quantitative method of data collection for determination of
$\mathrm{V}$ for additional criteria, with the use of the same scale as Step 2-1.

Step 2-3: Decision on the $\mathrm{W}$ for additional criteria based on the decision priorities by the decision maker(s). This should be balanced and in comparison with other $\mathrm{W}_{\mathrm{x}}$ from step 1.

Step 2-4: Normalizing the $\mathrm{W}$ matrix, as formulated in eq.1. As explained by Kien and Noraini [21], normalization is a method that translates all criteria into the matching dimension prior to relating with the weighted alternatives.

$$
\mathrm{W}_{\mathrm{x}}=\mathrm{W}_{\mathrm{x}} / \sum \mathrm{W}_{\mathrm{x}}
$$

Step 3: The weighted sum (WS) is determined by multiplying the weighting for every criterion by the associated numeric value that is allocated to each alternative, with the resulting values then summed up. This is shown in Eq.2.

$$
\mathrm{WS}\left(\mathrm{A}_{\mathrm{x}}\right)=\left(\mathrm{W}_{\mathrm{x}}, \mathrm{V}_{\mathrm{x}}\right)
$$

Step 4: Eq.3 shows that for each alternative (Ax), the WS can be determined by totalling the respective resulting values.

$$
\operatorname{FR}\left(\mathrm{A}_{\mathrm{j}}\right)=\sum_{\mathrm{y}}\left(\mathrm{WS}\left(\mathrm{A}_{\mathrm{x}}\right)\right) \mathrm{y}\left(\mathrm{WSA}_{\mathrm{x}}\right)
$$

Step 5: Finally, by comparing the FR, all alternatives with maximums that match the criteria can be enumerated from most to least preferred option. The alternative featuring the highest FR is superior alternative in terms of selection.

\section{Result}

A recently published case-study with WSM decision making by Sorooshian [13] is adapted to validate the proposed modified WSM. The case study was for a business that had three alternative machines to choose from and purchase one. The Machines were named Brand A, Brand B, and Brand C. The decision-making team was a panel of three experts. Based on a nominal group technique, they collect information for two criteria of their decision-making: 'programmability' and 'reliability' of the machines. The term programmability refers to the capability of the machines to process different steps in a certain order based on the users programming; and the term reliability refers to the probability of trouble-free time in which the machine is working. However, for this study, we assume the existence of the third criteria, 'installation cost' of the machines which refers to the direct costs to get the machine ready to work.

The collected information for the first two criteria from the panel, as step1 and step 2-1 of the modified WSM, is shown in Table 1 . The average value for the inputs is shown in table 2. 
Table 1. Decision inputs for the first two criteria

\begin{tabular}{|c|c|c|c|c|}
\hline \multicolumn{5}{|c|}{ INPUTS: expert 1} \\
\hline Decision criteria & Weight for criteria (\%) & Brand A & Brand B & Brand C \\
\hline Programability & $\mathrm{W}_{1}=50$ & $V_{1,1}=7$ & $\mathrm{~V}_{1,2}=2$ & $V_{1,3}=5$ \\
\hline \multirow[t]{2}{*}{ Reliability } & $\mathrm{W}_{2}=50$ & $\mathrm{~V}_{2,1}=2$ & $\mathrm{~V}_{2,2}=1$ & $\mathrm{~V}_{2,3}=6$ \\
\hline & Total $=100 \%$ & & & \\
\hline \multicolumn{5}{|c|}{ INPUTS: expert 2} \\
\hline Decision criteria & Weight for criteria (\%) & Brand A & Brand B & Brand C \\
\hline Programability & $\mathrm{W}_{1}=40$ & $\mathrm{~V}_{1,1}=6$ & $\mathrm{~V}_{1,2}=7$ & $\mathrm{~V}_{1,3}=4$ \\
\hline \multirow[t]{2}{*}{ Reliability } & $\mathrm{W}_{2}=60$ & $\mathrm{~V}_{2,1}=4$ & $\mathrm{~V}_{2,2}=1$ & $\mathrm{~V}_{2,3}=6$ \\
\hline & Total $=100 \%$ & & & \\
\hline \multicolumn{5}{|c|}{ INPUTS: expert 3} \\
\hline Decision criteria & Weight for criteria (\%) & Brand A & Brand B & Brand C \\
\hline Programability & $\mathrm{W}_{1}=42$ & $\mathrm{~V}_{1,1}=7$ & $\mathrm{~V}_{1,2}=5$ & $\mathrm{~V}_{1,3}=3$ \\
\hline \multirow[t]{2}{*}{ Reliability } & $\mathrm{W}_{2}=58$ & $\mathrm{~V}_{2,1}=4$ & $\mathrm{~V}_{2,2}=1$ & $\mathrm{~V}_{2,3}=6$ \\
\hline & Total $=100 \%$ & & & \\
\hline
\end{tabular}

Table 2. Average of the experts' input

\begin{tabular}{|c|c|c|c|c|}
\hline Decision criteria & Weight for criteria (\%) & Brand A & Brand B & Brand C \\
\hline Programability & $\begin{array}{c}\mathrm{W}_{1}=(50+40+42) / 3 \\
=44\end{array}$ & $\begin{aligned} V_{1,1}= & (7+6+7) / 3 \\
= & 6.6\end{aligned}$ & $\mathrm{~V}_{1,2}=3$ & $\mathrm{~V}_{1,3}=3.2$ \\
\hline Reliability & $\mathrm{W}_{2}=56$ & $\mathrm{~V}_{2,1}=3.3$ & $\mathrm{~V}_{2,2}=1$ & $\mathrm{~V}_{2,3}=6$ \\
\hline
\end{tabular}

As step 2-2 and 2-3 of the modified WSM, the installation cost of the machines obtains from a different source, the contractor's quotation, as shown in table 3. The decision maker considers the information and weights the criteria as shown in the last row of the table; the lower-priced installation, the better.

Table 3. Input for the third criteria

\begin{tabular}{|c|c|c|c|c|}
\hline \multicolumn{3}{|c|}{ INPUTS: contractor's quotation } \\
\hline Decision criteria & Weight & Brand A & Brand B & Brand C \\
\hline Installation cost & & $\$ 1500$ & $\$ 1500$ & $\$ 2000$ \\
\hline Weight by the decision maker & $50 \%$ & 4 & 4 & 2 \\
\hline
\end{tabular}

The decision making table, as shown in table 4, is based on step 2-4 of the modified WSM.

Table 5 is presenting the result of step 4 and 5.

After calculation of step 3 and 4, the final FR, in step 5, for Brand A, Brand B, and Brand C are 4.4, 2.4, and 3.7 respectively. Based on the presented result, machine Brand A which has the uppermost FR, is greatest option matching the listed decision criteria than other machines. However, machine Brand B with the lowest FR is with the lowest satisfactory level. In the end, the case-study result validates the feasibility of the modified WSM.

Table 4. Decision making data

\begin{tabular}{|ccccc|}
\hline Decision criteria & Weight & Brand A & Brand B & 3 \\
\hline Programability & $\mathrm{W}_{\mathrm{x}},=44 /(44+56+50)=0.29$ & 6.6 & 3.3 & 1 \\
\hline Reliability & $\mathrm{W}_{\mathrm{x}}=56 /(44+56+50)=0.37$ & 6 & 4 \\
\hline Installation cost & $\mathrm{W}_{\mathrm{x}},=50 /(44+56+50)=0.33$ & 4 & 4 \\
\hline
\end{tabular}

Table 5. WSM

\begin{tabular}{|cccc|}
\hline Decision criteria & Brand A & Brand B & Brand C \\
\hline Programability & $\mathrm{WS}\left(\mathrm{A}_{\mathrm{x} 1,}\right)_{1}=0.29 \times 6.6=1.9$ & $\mathrm{WS}\left(\mathrm{A}_{\mathrm{x} 2,1}\right)=0.8$ & $\mathrm{WS}\left(\mathrm{A}_{\mathrm{x} 3,3}\right)=0.9$ \\
\hline Reliability & $\mathrm{WS}\left(\mathrm{A}_{\mathrm{x} 1,2}\right)=1.2$ & $\mathrm{WS}\left(\mathrm{A}_{\mathrm{x} 2,2}\right)=0.3$ & $\mathrm{WS}\left(\mathrm{A}_{\mathrm{x} 3,3}\right)=2.2$ \\
\hline Installation cost & $\mathrm{WS}\left(\mathrm{A}_{\mathrm{x} 1,3}\right)=1.3$ & $\mathrm{WS}\left(\mathrm{A}_{\mathrm{x} 2,3}\right)=1.3$ & $\mathrm{WS}\left(\mathrm{A}_{\mathrm{x} 3,3}\right)=0.6$ \\
\hline
\end{tabular}




\section{Conclusions}

The proposed modifies WSM can solve the issue of decision making with a different source of information; however, it needs a valid additional source(s) of information for weighting the additional criteria. Further modification of the proposed method could be in Step 2-2 where the decision maker uses a source of information for determination of $\mathrm{V}$ for additional criteria; in case when the scale of weights for additional criteria is not matched with the scales of weighted main criteria. For this case a sub-step of normalization for matrix $\mathrm{V}$ is suggested before proceeding with the calculation of matrix $\mathrm{W}$.

Nonetheless, there is a need for future studies to comment on the implementation of the modified WSM. Last but not least, this article could be a source for further improvement of other MADM methods.

\section{REFERENCES}

[1] M. Aruldoss, T. M. Lakshmi, V. P. Venkatesan. A survey on multi criteria decision making methods and its applications, American Journal of Information Systems, Vol. 1, No. 1, 31-43, 2013.

[2] R. H. Ansah, S. Sorooshian, Sh. Mustafa. Analytic Hierarchy Process Decision Making Algorithm, Global journal of pure and applied mathematics, Vol.11, No.4, 2403-2410, 2015.

[3] T. Almulhim. Development of a Hybrid Fuzzy Multi-Criteria Decision Making Model for Selection of Group Health Insurance Plans. (Doctor of Philosophy), The University of Manchester, 2014.

[4] E. K.Zavadskas, K. Govindan, J. Antucheviciene, Z. Turskis. Hybrid multiple criteria decision-making methods: a review of applications for sustainability issues, Ekonomska istraživanja, Vol. 29, No. 1, 857-887, 2016.

[5] S. A. M. Ali, S. Sorooshian, Ch. J. Kie. Modelling for causal interrelationships by DEMATEL. Contemporary Engineering Sciences, Vol.9, No.9, 403-412, 2016.

[6] A. A. Zavareh. Fuzzy dynamic hybrid MCDM method for supplier evaluation and selection. (Doctor of philosophy), Technology university of Malaya, Kuala lumpur, 2014.

[7] A. Jamalizadeh, S. Sorooshian. Merits of industrial clustering: Case of date's industry of Iran. Quality - Access to Success, Vol.18, No.159, 123-126, 2017.

[8] S. Sorooshian, T. A. Fen. Applicability of manufacturing lean tools in service operations, International Journal of Mechanical Engineering and Technology, Vol.8, No.7, 53-60, 2017.

[9] R. Ramlan, S. S. Omar, J. Y. Wong, S. Sorooshian. SME SWOT ranking for strategic planning using analytic hierarchy process (AHP), Information (Japan), Vol.19, No.10, 4755-4760, 2016.

[10] S. Sorooshian, L. Z. En, M. G. Maarof. A. Q. Adeleke.
Lean tools application failure. International Journal of Applied Business and Economic Research, Vol.15, No.18, 425-443, 2017.

[11] S. Sorooshian, J. Dodangeh. Modeling on performance drivers of project management, Advances in Environmental Biology, Vol.7, No.13, 3890-3894.

[12] S. Sorooshian. Study on unbalanceness of the balanced scorecard. Applied Mathematical Sciences, 4163-4169, doi:10.12988/ams.2014.45337, 2014.

[13] S. Sorooshian. Group decision making with unbalanced-expertise. Paper presented at the Journal of Physics: Conference Series, Vol. 1028, No. 1, doi:10.1088/1742-6596/1028/1/012003, 2018.

[14] A. Salehi, M. Izadikhah. A novel method to extend SAW for decision-making problems with interval data, Decision Science Letters, Vol.3, No.2, 225-236, 2014.

[15] Sh. Chou, Y. Chang, Ch. Shen. Fuzzy simple additive weighting system under group decision-making for facility location selection with objective/subjective attributes. European Journal of Operational Research, Vol.189, No.1, 132-145, 2008.

[16] R. Talebanpour, M. Javadi. Decision-making for flexible manufacturing systems using DEMATEL and SAW. Decision Science Letters, Vol.4, No.3, 363-372, 2015.

[17] S. Sorooshian. Alternative method for evaluation of dagang deep drilling applications, Electronic Journal of Geotechnical Engineering, Vol.20, No.13, 5209-5212, 2015.

[18] A. S. Kumar, N. Suresh. Operations Management: New Age International, New Age International Publisher, 2009.

[19] V. Maxville. Strategies for the intelligent selection of components, PhD thesis, Edith Cowan University, 2012.

[20] H. Solberg, K. M. Dahl. COTS Software Evaluation and Integration Issues. Norwegian Institute of Technology and Science, Norwegian University of Technology And Science, http://www.idi.ntnu.no/grupper/su/sif8094-reports/2001/p1 4.pdf, 2001.

[21] H. T. Kien, A. Noraini. Weighted Sum-Dijkstra's Algorithm in Best Path Identification based on Multiple Criteria, Journal of Computer Science \& Computational Mathematics, Vol.8, No.3, 107-113, 2018. 